\title{
Application of herbs in functional dairy products - a review
}

\begin{abstract}
Herbs have multifarious role such as food flavourings, preservative and as medicinal ingredient. Various herbs are documented for their therapeutic properties viz., antioxidative, antihypertensive, anti-inflammatory, antidiabetic, antimicrobial, etc. Some of the important herbs dealt in this review include Ashwagandha, Arjuna, Turmeric, Sage, Cinnamon, Cumin, Garlic, Fenugreek, Peppermint, Basil and Aloe vera. The examples of some spice and herbs containing antioxidants include basil, cinnamon, clove, dill, ginger, mint, oregano, rosemary, saffron, sage, thyme, etc., while herbs showing hypotensive properties include garlic, celery, tea, ajwain, ginger, lavender, basil, radish, rauwolfia, sesame, etc. Terminalia arjuna based sitosterol is considered as one of the best heart tonic for healthy cardiovascular system. Few herbs can help in extending the shelf life of dairy products (especially fermented dairy products) especially through their suppressing effect on fungi and bacteria. Hence, judicious use of herb application in dairy products may result in raising their nutritional and medicinal values and enable development of value-added dairy products. Fortification of herbs in dairy products could help in providing value-added, functional dairy foods at the same time boost the sale of important herbs.
\end{abstract}

Keywords: herbs, functional food, neutraceutical, fortification, dairy foods, cardiovascular diseases, antihypertensive property, oligomeric proantho cyanidines, antioxidants
Volume 5 Issue 3 - 2017

\author{
Lalita Oraon,' Jana Atanu, ${ }^{2}$ Prajapati PS, ${ }^{3}$ \\ Priyanka Suvera ${ }^{4}$ \\ 'National Dairy Development Board, India \\ ${ }^{2}$ Dairy Technology Department, Anand Agricultural University, \\ India \\ ${ }^{3}$ Dairy Technology Department, Mansinhbhai Institute of Dairy \\ \&Food Technology, India \\ ${ }^{4}$ Sardar Krushinagar Dantiwada Agricultural University, India
}

Correspondence: Atanu Jana, Department of Dairy

Technology, SMC College of Dairy Science, Anand Agricultural University, Anand - 388 । I 0, Gujarat State, India, Tel +9| 937 50I 2630, Fax +9| 0269226 I3 |4, Email atanudt@aau.in

Received:September 23, 2016 | Published: May 18, 2017
Abbreviations: MIC, minimum inhibitory concentration; WHO, world health organization; ACE, angiotensin converting enzyme; ROS, reactive oxygen species; CVDs, cardio vascular diseases; BHA, butylated hydroxy anisole; BHT, butylated hydroxy toluene; TBHQ, tertiary butyl hydro quinone; SFE, supercritical fluid extraction; NDRI, national dairy research institute; TS, total solids; USA, united states of america

\section{Introduction}

Since the ancient times, herbs have been used not just as food flavorings, but also as medicine and preservatives. There is a significant linkage between food habit and disease prevention; the effects of food on diseases such as diabetes, obesity, osteoporosis, hypertension and cardiovascular disease are documented in literature. ${ }^{1}$ The indigenous knowledge on medicinal plants is gaining worldwide recognition. India is the largest producer of medicinal herbs and is referred to as the 'Botanical Garden of the World. ${ }^{2}$ With the emergence of fortified foods, there is a worldwide increase in health awareness and interest in adding herbs as prized food additive in dairy and food products. ${ }^{3}$ Due to the increased consumer awareness and interest to follow healthy nutrition and dietary strategy in achieving health benefits from foods beyond their basic nutrition, the market for value-added functional foods has expanded manifold. ${ }^{4}$ World Health Organisation survey indicated that about $70-80 \%$ of the world population rely on non-conventional medicine mainly on herbal sources in their primary healthcare. ${ }^{5}$ Over $60 \%$ of the world's population and $80 \%$ in developing countries depends directly on plants for their medical purposes. ${ }^{6}$

Herbs have found many uses in treating number of diseases and their herbal extracts can be used in pharmaceuticals, ayurvedic formulation, confectionery, nutritional foods, ready-to-drink mixes, instant foods, seasonings, dairy products, seasoning blends, etc. Therefore, fortification of herbs in dairy products could provide value added, functional dairy product. The objective of collating literature on some important herbs will unravel the mysteries, enabling us to know the causative factors for alleviating health issues otherwise plaguing certain individuals. Moreover, use of some specific herbs will help in shelf life extension of otherwise perishable dairy products.

\section{Functional properties of herbs}

Natural antioxidants, derived from plant sources are presumed to be safe as they occur in nature and are being used by human being from ancient time. ${ }^{7}$ Antioxidants help in delaying the oxidation of molecules by inhibiting the initiation or propagation of oxidizing chain reactions by free radicals and may reduce oxidative damage to the human body. ${ }^{8,9}$ The antioxidant properties of herbs are due to presence of some vitamins, flavonoids, terpenoids, carotenoids and phytoestrogens. Some examples of spice and herbs containing antioxidants are: basil, cinnamon, clove, dill, ginger, mint, oregano, rosemary, saffron, sage, thyme, etc. ${ }^{10}$

There are arrays of naturally occurring medicinal herbs that have hypotensive/antihypertensive potential. These herbs may help in regulation of blood pressure by stimulating the physiological systems in humans. Some example of herbs showing hypotensive properties are garlic, celery, tea, ajwain, ginger, lavender, murungai, basil, kudzu, radish, rauwolfia, sesame, etc. Angiotensin Converting Enzyme (ACE) inhibitors present in herbs may inhibit angiotensinconverting enzyme, a component of the blood pressure-regulating renin-angiotensin system, thereby lowering the blood pressure. ${ }^{11,12}$ The examples of few important herbs that have conferred medicinal or functional properties to dairy foods are dealt below. 


\section{a. Ashwagandha (Withania somnifera)}

Ashwagandha is referred to as Indian ginseng or winter cherry. One of the most esteemed medicinal plant used in Indian Ayurveda since centuries. It hails from Solanceae family, grown in Africa, the Mediterranean, and India. Ashwagandha is considered to be a vitalizer, adaptagen, facilitating the ability to withstand stressors, and has antioxidant properties. Sitoindosides and acylsterylglucosides in Ashwagandha are antistress agents. Ashwagandha is characterised by the presence of steroidal lactones, alkaloids and flavonoids. Their root contains maximum amount of alkaloids- nicotine, sominie, somniferin, somniferinine, withanine, withanonine, withanolides, etc. Roots of the plant shows hypotensive, bradycardiac, antitumor, respiratory stimulant activities and immuo-stimulating effect. ${ }^{13,14}$

\section{b. Turmeric (Curcuma longa)}

Turmeric is widely used as a spice, preservative, colouring matter and has wide range of medicinal and pharmacological applications. It exhibits anti-inflammatory, anti-HIV, anti-bacterial, antioxidant, nematocidal, antiparasitic, antispasmodic and anti-carcinogenic activities. Niranjan and Prakash (2008) reported that it is a potent scavenger of a variety of Reactive Oxygen Species (ROS) including superoxide anion, hydroxyl radical, peroxynitrite, etc. A total of 720 compounds, including 102 diphenylalkanoids, 19 phenylpropene derivatives, 529 terpenoids, 15 flavonoids, 7 steroids, 3 alkaloids and 44 compounds of other types isolated or identified from 32 species, have been phytochemically investigated in Curcuma longa. The biological activities of plant extracts mainly involve anti-inflammatory and antitumor activities. ${ }^{15}$

\section{c. Arjuna (Terminalia arjuna)}

Terminalia arjuna Wight \& Arn is a deciduous and evergreen tree that belongs to Combretaceae family. It is found in abundance throughout Indo-sub-Himalayan tracts of Uttar Pradesh, South Bihar, Madhya Pradesh, Delhi and Deccan region near ponds and rivers. It is also found in forests of Sri Lanka, Myanmar and Mauritius. Terminalia arjuna shows potential antioxidant and free radical scavenging activity due to presence of more amount of flavonoid and phenolic content. ${ }^{16}$ The plant is rich source of natural antioxidants and hence finds usage in both Ayurvedic and Yunani systems of medicine. It is reported to possess properties such as styptic, anthelmintic, alexiteric, tonic, and useful in fractures, heart diseases, urinary discharges, biliousness, ulcers, asthma, tumors, anemia, excessive perspiration, etc. Terminalia arjuna based phytochemicals are considered as one of the best heart tonic useful for healthy cardiovascular system. The sitosterol present in this herb lowers the cholesterol in blood serum by inhibition of cholesterol absorption. The active components of Terminalia arjuna are tannins, triterpenoid saponin (arjunic acid, arjunolic acid, arjungenin, and arjunglycosides). Flavonoids (arjunone, arjunolone, luteolin), gallic acid, ellagic acid, Oligomeric Proantho Cyanidines (OPCs), phytosterols, calcium, magnesium, zinc and copper. ${ }^{17,18}$

\section{d. Sage (Salvia triloba)}

Sage is the dried leaf of a mint family. The leaves of Sage plant are well known for their anti-oxidative properties and antiinflammatory activities. The major antioxidant compounds in sage include carnosol, carnosic acid, rosmadial, rosmanol, epirosmanol and methylcarnosate. ${ }^{19}$ Essential oil from sage is known to possess well-known antioxidant properties. ${ }^{20}$ The oil extract of sage has been found to possess antimicrobial activities against a wide range of bacteria, which are mainly due to the cineole component. It is used as a flavouring and antioxidant in cheeses, pickles, vegetables, processed foods and beverages. ${ }^{21}$

\section{e. Cinnamon(Cinnamomum verum, synonym C. Zeylanicum)}

Cinnamon is a herb traditionally used by many ancient cultures. They are small evergreen tree belonging to the family Lauraceae, native to Sri Lanka and South India. In addition to being used as a spice and flavouring agent, cinnamon is added in certain food for mouth refreshing effects. ${ }^{22}$ Cinnamon has been implicated in reducing the risk of colon cancer, acts as a coagulant and prevents bleeding. ${ }^{23,24}$ Cinnamon also increases the blood circulation in the uterus and advances tissue regeneration. The essential oils of cinnamon have antimicrobial, antifungal, antioxidant and antidiabetic. ${ }^{25}$ Cinnamon shows complete antibacterial effect against food borne pathogens such as Salmonella typhi, Salmonella paratyphi A, E. Coli, S. Aureus, Pseudomonas fluorescens and Bacillus licheniformis. ${ }^{26,27}$ They exert inhibition against fungal strains too. The Minimum Inhibitory Concentration (MIC) values for cinnamon essential oil ranged from 1.25 to $5.0 \% .^{28}$

\section{f. Cumin(Cuminum cyminum)}

Cumin is a small annual herbaceous plant that is a member of the aromatic plant family Umbelliferae. Cumin is cultivated in India, Morocco, Iran, Turkey, China and the America. The seeds of the plant are used to add flavour to spicy dishes. They are also used as an appetite stimulant and to ease stomach disorders. ${ }^{29}$ A powder suspension of the cumin inhibits mycelium growth, toxin production or aflatoxin production by Aspergillus ochraceus, Candida versicolor and Candida flavus. The antibacterial action has also been seen against a range of useful and pathogenic gram-positive and gram-negative bacterial strains. ${ }^{30}$ Mainly cuminaldehyde, carvone, limonene and linalool and to a certain extent limnonene, eugenol, pinene, etc. contributes to the antimicrobial activity of cumin. ${ }^{31}$ The fatty oil (mainly petroselic acid) present in cumin exerts antimicrobial effect too. Antifungal activity of cumin is recorded against food, human pathogens, including dermatophytes, vibrio spp., yeasts, aflatoxins and mycotoxin producers. ${ }^{32}$ The MIC values for cumin essential oil ranged from 6.25 to $12.5 \%{ }^{33}$

\section{g. Garlic (Allium sativum)}

Garlic is used as important ingredient in some Indian spicy dishes. It is a rich source of phytochemicals and organosulfur compounds showing health benefits and anti-aging effects. It is used to spice food, cure colds, heal infections, and treat ailments like heart disease and cancer. ${ }^{34}$ Allicin or diallyl thiosulphinic acid is the main constituent of garlic that has antimicrobial activity against both gram-positive and gram-negative bacteria. Allicin is enzymatically produced from its precursor aliin viathe intermediate product of allylsulfenic acid. ${ }^{35}$ Many studies have demonstrated efficacy of garlic extract inreducing the growth of many pathogens including S. Aureus, S. Albus, S.Typhi, E. Coli, L. Monocytogenes, A. Niger, Acari parasitus, Pseudomonas aeruginosa and Proteus morganni. ${ }^{36,37}$

\section{h. Fenugreek (Trigonella afoenum-graecum Leguminosse)}

Fenugreek is found all over India and the fenugreek seeds are usually used as one of the major constituents of Indian spices. A novel amino acid from fenugreek seeds, 4-hdroxyleucine, increased glucose stimulated insulin release by isolated islet cells in both rats and 
humans. Oral administration of 2 and $8 \mathrm{~g} / \mathrm{kg}$ of plant extract produced dose dependent decrease in the blood glucose levels in diabetic rats. Administration of fenugreek seeds also improved glucose metabolism and normalized creatinine kinase activity in heart, skeletal muscle and liver of diabetic rats. It also reduced hepatic and renal glucose-6phosphatase and fructose-1,6-biphosphatase activity. This plant also shows antioxidant activity. ${ }^{2}$

In India, the ground seeds are used in spice mixtures and as a condiment, and therefore constitute an important ingredient in Chutneys and spice blends. In Egypt, these seeds are either eaten raw after sprouting or are used to make a confection following roasting, grinding and cooking them with treacle and sesame seeds. In USA, fenugreek seed extract is used as principal flavoring ingredient in simulated maple syrup and other products. ${ }^{38}$

\section{i. Peppermint (Mentha piperita)}

Peppermint plant grows to about 2-3 feet tall. Dark green, fragrant leaves grow opposite white flowers. Peppermint is native to Europe and Asia, is naturalized to North America, and grows wild in moist, temperate areas. Some varieties are indigenous to South Africa, South America and Australia. The leaves and stems, which contain menthol (a volatile oil), are used medicinally and as flavouring in food. ${ }^{39}$

Peppermint, a popular flavouring for tea is also used to soothe an upset stomach or to aid digestion. It has a calming and numbing effect, and is often used to treat headaches, skin irritation, nausea, diarrhea, menstrual cramps, flatulence, and anxiety associated with depression. Menthol and methyl salicylate, the main components in peppermint, have antispasmodic effects, with calming effects on the gastrointestinal tract. Several studies support the use of peppermint for indigestion and irritable bowel syndrome..$^{40}$

\section{j. Basil (Ocimum basilicum)}

Basil is commonly known as Tulsi. Since ancient times, this plant is known for its medicinal properties. The aqueous extract of leaves of Ocimum sanctum showed significant reduction in blood sugar level in both normal and alloxan induced diabetic rats. Significant reduction in fasting blood glucose, uronic acid, total amino acid, total cholesterol, triglyceride and total lipid indicated the hypoglycemic and hypolipidemic effects of tulsi in diabetic rats. This plant also showed anti-asthemitic, anti-stress, antibacterial, anti-fungal, antiviral, antitumor, gastric anti-ulcer activity, antioxidant, anti-mutagenic and immuno-stimulant activities. ${ }^{41}$ Peppermint and Basil (Ocimum basilicum) are traditionally grown crops in Europe and Central Asia for the production of fresh herb, dry leaves or essential oils. ${ }^{42}$ These plants portions find their applications as culinary herb or as minor adjuncts to salads and herbal tea and as aromatic agents in the food, pharmaceutical, functional food and nutraceuticals industries. ${ }^{21,43}$

\section{k. Aloe vera (Aloe barbadensis miller)}

Aloe vera has a long history of use as a topical and oral therapeutic. It is an acaulescent, perennial plant, and belongs to Xanthorrhoeaceae family. Aloe vera is a native plant of the Mediterranean region but is found all over the world. The Aloe vera leaf can be divided into two main fractions: the green skin, which is rich in 1,8-dihydroxyanthraquinone derivatives and their glycosides, and the colourless pulp that is richer in complex carbohydrates. Mucilaginous jelly like parenchyma is referred to as Aloe vera pulp or gel. This gel has a large content of water (95-99\%), and contains proteins, lipids, amino acids, vitamins, enzymes, inorganic compounds, and small organic compounds in addition to carbohydrates. Acemannan (acetylated gluconmanan), also known as carrysin, is the best known among the polysaccharides found in Aloe vera gel. Aloe vera is a source of essential micronutrients and active phyto-chemicals such as ascorbic acid, tocopherols and phenolic compounds which are able to reduce the free radicals that cause reactions of oxidation associated with CVD, carcinogenesis and aging. Many biological activities, including antimicrobial, laxative, protection against radiation, antioxidant, antiinflammatory, anti-tumour, anti-diabetic, antiallergic, as well as hypoglycaemic, gastroprotective, immunomodulatory and wound healing effects, have been attributed to this plant gel. ${ }^{44}$

\section{Processing of herbs}

Herbs and spices contain both volatile and non-volatile compounds and oils. Most spice flavours are due to volatile oil, but volatile flavour compounds can be generated from non-volatile oil by heating. Flavour components tend to become weak or disappear at high temperatures and flavour components of spices are become more volatile with increasing temperature during processing. ${ }^{45}$

Irradiation helps to extend the shelf life of herbs and to reduce the food-related health hazards caused by pathogenic microorganisms. At present, radiation treatment is permitted for various categories of food and food ingredients in several countries. ${ }^{46,47}$ Supercritical Fluid Extraction (SFE) has gained considerable acceptance nowadays as an alternative to conventional solvent extraction for separation of organic compounds from herbs. SFE has been successfully used for extraction of a variety of organic compounds from herbs and plants. SFE can be efficiently used to clean up the pesticides present in herb medicines. ${ }^{48}$

\section{Application of herbs in dairy products}

Judicious application of several herbs in various forms (i.e. powder, essential oils, etc.) in few dairy products has been successfully attempted. The description of each dairy product incorporated with herbs has been discussed herein.

\section{Ghee (clarified butterfat)}

Herbs contain high amounts of phenolic compounds which possess potent antioxidant properties. The natural antioxidant properties of herbs have made their use in the formulation of functional foods specifically targeted for the people suffering from Cardio Vascular Diseases (CVDs). ${ }^{49}$ Presently, the herbal ghee being marketed in the global market is mostly sold as medicine (medicinal ghee). These products possess typical flavour, bitter or pungent taste and a dark colour. Such therapeutic preparations are therefore not acceptable for regular consumption. At National Dairy Research Institute (NDRI), Karnal, India herbal ghee incorporating functional attributes of Arjuna herb has been developed for providing beneficial effects against CVD; such product had greater stability against oxidation as compared to conventional ghee. The consumer acceptability of such Arjuna ghee was very good..$^{50}$

The antioxidant activities of vidarikand (Pueraria tuberosa), shatavari (Asparagus racemosus) and ashwagandha (Withania somnifera) extracts, both as aqueous and ethanolic extracts, were evaluated as against synthetic antioxidant BHA. The active components of vidarikand are puerarin, daidzein, genistein and daidzin. ${ }^{51}$ The ethanolic extract showed more antioxidant activity than their aqueous counterpart, owing to greater phenolic content in the former extract. Hence, the ethanolic extract of the herb were more effective in 
preventing the development of peroxide value and conjugated diene in ghee compared to their aqueous extract. The antioxidant activity of the herbs decreased in the order: vidarikand $>$ ashwagandha $>$ shatavari. The ethanolic extract of Vidarikand had the maximum antioxidant activity among the herbs tested. ${ }^{52}$

Asparagus racemosus (shatavari) are steroidal glycosides, saponins, polyphenols, flavonoids, galactose and vitamins ${ }^{53}$ and Withania somnifera are steroidal lactones (withanolides), sitoindosides and steroidal alkaloids. Withania somnifera is one of the major herbal components of geriatric tonics, this plant is also claimed to have potent aphrodisiac, rejuvenative and life prolonging properties. ${ }^{54}$ Asparagus racemosusis reported to have immuno-stimulant, anti-hepatotoxic and anti-oxytocic activities ${ }^{55}$ and antioxidant and anti-diarrheal activities in laboratory animals. ${ }^{56}$

Rajnikant \& Pati ${ }^{50}$ developed herbal ghee using T. Arjuna as herb focussing on the herb's anti-oxidative properties. Parmar et al. ${ }^{17}$ found that addition of ethanolic extract of T. Arjuna bark at $7 \%$ by weight was highly effective in retarding the auto-oxidation of both cow and buffalo ghee during storage. Ethanolic extract of Arjuna herb showed significant ability to enhance the antioxidant potential of ghee; the efficacy was more pronounced in case of cow ghee compared to buffalo ghee. The shelf life (accelerated test) of the Arjuna herbal ghee at $80 \pm 1^{\circ} \mathrm{C}$ was 8 days as compared to just 2days for control ghee sample (devoid of herb).

Sage (Salvia officinalis) and Rosemary (Rosmarinus officinalis) extracts have been the most widely used herbs for prolonging the shelf life of ghee and butter oil. ${ }^{57}$ These extracts have antioxidant activity many times stronger than that of synthetic antioxidants (i.e. Butylated Hydrozy Anisole [BHA], Butylated Hydroxy Toluene [BHT]). ${ }^{58}$

\section{Yogurt and Labneh (concentrated yoghurt)}

Herbal yoghurt was prepared using cinnamon andlicorice, incorporating probiotic bacteria. The presence of herbs did not affect the probiotic population during storage and there were no significant differences in $\mathrm{pH}$ and total titratable acidity between herbal-yogurts and plain-yogurt during storage. Water extract of cinnamon-yogurt showed the highest inhibition effect on Helicobacter pylori growth as compared to licorice-yogurt and control yogurt. ${ }^{59}$ Different types of herbal yogurts were prepared by mixing pretreated herbs with standardized milk using strains of L. Acidophilus and L. Plantarum $(1: 1 \mathrm{v} / \mathrm{v})$ and incubated at $40^{\circ} \mathrm{C}$ for $6 \mathrm{~h}$; the herbs were namely Tulsi leaf (Ocimum sanctum), Pudina leaf (Mentha Arvensis) and coriander leaf (Coriandrum sativum). They reported greater $\beta$-D-galactosidase enzymatic activity in herbal yoghurt compared to control yogurt (without any herbs). Among the herbal yogurts, Tulsi yogurt showed the maximum $\beta$-D-galactosidase activity. ${ }^{60}$

Yoghurt containing cinnamon $(6.0 \%$ cinnamon extract dissolved in 1.01 milk) could be successfully stored under refrigeration for up to 28days; the Lactobacillus species count in such yoghurt was $19.46 \times 10^{6} \mathrm{cfu} / \mathrm{ml}$ when fresh; the Streptococcus thermophilus count increased in yoghurt containing cinnamon up to 7days, when stored under refrigeration. ${ }^{59}$ Labneh is basically concentrated yoghurt quite popular in the Middle East. Labneh (23.0\% TS) containing $0.2 \mathrm{ppm}$ each of thyme, marjoram and sage essential oils had extended shelf life (by 21days over control) at $5^{\circ} \mathrm{C}$. The control Labneh (devoid of essential oil) showed presence of yeast and mold from $14^{\text {th }}$ day of storage onwards, when stored at $5^{\circ} \mathrm{C} .{ }^{61}$ Labneh $(23.70 \% \mathrm{TS})$ containing $0.3 \%$ of cinnamon essential oil had greater shelf life (i.e. 8 days in excess) as compared to control product, when stored at $6^{\circ} \mathrm{C} .{ }^{62}$

\section{Dahi (Indian yogurt) and lassi (fermented drink)}

At NDRI, Karnal, India a functional Lassi and Dahi were developed by supplementing the herb Aloe vera and probiotics. Animal study of such herbal Lassi revealed that it exerted better immunoprotective effects as compared to control Lassi. Supplementation of Aloe vera supported the growth of probiotic strain in fermented product. The probiotic viability was $>7 \log _{10} \mathrm{cfu} / \mathrm{ml}$ during 12 days storage period. ${ }^{63}$

\section{Yogurt spread}

A herbal flavoured spread based on yogurt was developed by Kumar et al. ${ }^{64}$ Yogurt concentrate $(60 \%$ TS) was prepared by allowing the whey to drain from yoghurt. To this yogurt concentrate, salt and coriander were added at the same rate of $2 \%$ by weight. For optimization of mint level, the mashed raw leaves were added at 2, 4 and $6 \%$ by weight of yoghurt concentrate. The yoghurt spread prepared with $2 \%$ mint had higher sensory scores than the ones prepared using higher (i.e. 4 and $6 \%$ levels) rate of addition. The shelf life of the spread was 10 days when stored at $5^{\circ} \mathrm{C}$. Such mint flavoured yoghurt spread is recommended for use in sandwiches, burgers, chapattis and other leavened bakery items.

\section{Shrikhand (sweetened and flavoured oncentrated yoghurt )}

Shrikhand being a semi soft, sweetish sour, whole milk product prepared from lactic fermented curd can easily harbor herbs/herbal extracts without undergoing significant changes in its sensory quality. Ashwagandha powder was incorporated at the rate of 0 to $0.7 \%$ by weight of Chakka (concentrated yogurt obtained by partial draining of whey from yoghurt) in the manufacture of Shrikhand(sweetened and flavoured concentrated yoghurt); cane sugar was used at the rate of $40 \%$ by weight. Shrikhand prepared using $0.5 \%$ ashwagandha powder was superior in terms of organoleptic characteristics as compared to experimental shrikhand containing 0.3 and $0.7 \%$ powder and control Shrikhand (no addition of herb). The herb containing shrikhand were acceptable up to 52days when stored under refrigeration temperature. ${ }^{65}$

\section{Ice cream}

Different forms of ginger i.e., ginger juice @ 4\%, ginger shreds @ 4\%, sugar syrup treated ginger shreds @ 6\% and ginger powder @ $1 \%$ were used to prepare 'ginger flavoured herbal ice cream' and compared against a controlice cream made using vanilla flavouring. Incorporation of ginger juice or ginger shreds (sugar syrup treated) at rate of $4 \%$ by weight of ice cream mix is recommended for obtaining acceptable quality 'ginger flavoured ice cream' ${ }^{66}$ Trivedi et al. ${ }^{67}$ recommended incorporating basil juice @ 6\% and freeze dried basil powder @ 1\% by weight of ice cream mix in the preparation of 'basil flavoured herbal ice cream'. Basil variety Ocimum sanctum was preferred over $O$. Americanum, O. Basilicum and $O$. Gratissimum. Incorporation of basil juice led to decrease in fat, protein, carbohydrates, ash and acidity and an increase in $\mathrm{pH}$; melting resistance of ice cream was reduced.

\section{Paneer (directly acidified cheese like product)}

Turmeric was incorporated in Paneer coagulum at the rate of $0.4 \%$ and $0.6 \%$ by weight of expected yield of product. The Paneer samples containing $0.6 \%$ turmeric by weight, remained acceptable up to 12 days as against 7 days for control Paneer, when stored at $7 \pm 1{ }^{0} \mathrm{C} .{ }^{68}$ 
Turmeric powder when added to milk $(0.6 \%$ by weight of expected yield of Paneer) prior to heat treatment in Paneer making, helped in reducing the taste of raw turmeric in resultant product. ${ }^{68}$

\section{Sandesh (sweetmeat based on chhana)}

Sandesh is a chhana (obtained from milk by coagulation with acid) based sweetmeat product very popular in West Bengal, India. Paste of turmeric (Curcuma longa), coriander (Coriandrum sativum), curry leaf (Murraya koenigii L), spinach (Spinaciaoleracea) and aonla (Emblica officinalis) were incorporated separately at the 10\% level in Sandesh and were compared with control Sandesh added with synthetic antioxidants (viz. Tertiary Butyl Hydro Quinone [TBHQ, BHA, BHT). The researchers concluded that herbal Sandesh could be considered asvalue-added health food as compared to control Sandesh containing synthetic antioxidants. ${ }^{69}$ The antioxidative effect of herbal Sandesh decreased in the order: turmeric $>$ curry leaf $>$ aonla $>$ spinach $>$ coriander leaf. The total antioxidative potency of herbal Sandesh was lower than Sandesh samples containing TBHQ, but similar to those containing $200 \mathrm{mg} / \mathrm{kg}$ BHA and BHT $(1: 1 \mathrm{w} / \mathrm{w})$. Incorporation of coriander as herb resulted in increased shelf-life of herbal Sandesh up to 8days and 30days respectively, when stored at $30 \pm 1^{\circ} \mathrm{C}$ and $7 \pm 1^{\circ} \mathrm{C} .^{69}$

\section{Cheese}

A study reported that addition of clove essential oil (MIC of 2.0\%) showed antibacterial effect against $E$. Coli and Vancomycin-resistant Enterococci in Feta cheese stored at $7^{\circ} \mathrm{C}$ for 14 days. ${ }^{70}$

\section{Conclusion}

Since pre historical times, herbs have been used not just as food flavouring but also for its medicinal properties. The antimicrobial and antioxidant constituents present in herbs enables them to be used as effective preservatives. Incorporation of herbs in dairy product may results improvement the health and medical condition of human being. Herbal products with promising health benefit, should comply with the regulatory requirements with respect to safety, efficacy, quality testing and marketing authorization procedures. It should be devoid of any side effect. There is a need of systematic scientific studies and documentation.

\section{Acknowledgements}

None.

\section{Conflict of interest}

Author declares that there is no conflict of interest.

\section{References}

1. WHO. Diet, nutrition and the prevention of chronic diseases. Report of the joint WHO/FAO expert consultation. 2002.

2. Modak M, Dixit P, Londhe J, et al. Indian herbs and herbal drugs used for the treatment of diabetes. J Clin Biochem Nutr. 2007;40(3):163-173.

3. Ansari MM, Kumar DS. Fortification of food and beverages with phytonutrients. Food Pub Health. 2012;2(6):241-253.

4. Kumar Prevesh, Kumar Nirdesh, Omer Tushar. A review on neutraceutical Critical supplement for building a healthy world. World J Pharmacy \& Pharmaceutical Sci. 2016;5(3):579-594.
5. Chan K. Some aspects of toxic contaminants in herbal medicines. Chemosphere. 2003;52(9):1361-1371.

6. Shrestha PM, Dhillon SS. Medicinal plant diversity and use in the highlands of Dolakha district, Nepal. J Ethnopharmacol. 2003;86(1):81-96.

7. Madsen HL, Bertelsen G. Spices as antioxidants. Trends Food Sci Technol. 1995;6:271-277.

8. Namiki M. Antioxidant/antimutagens in food. Crit Rev Food Sci Nutr. 1990;29(4):273-300

9. Ismail A, Marjan ZM, Foong CW. Total antioxidant activity and phenolic content in selected vegetables. Food Chem. 2004;87(4):581-586.

10. Carlsen MH, Halvorsen BL, Holte K, et al. The total antioxidant content of more than 3100 foods, beverages, spices, herbs and supplements used worldwide. Nutr J. 2010;9(1):1-11.

11. Matsui T, Matsumoto K. Antihypertensive peptides from natural resources. In: Khan Math, editor. Advances in Phytomedicine. 1st ed. USA: Elsevier Publisher; 2006. p. 273-299.

12. Korhonen H, Pihlanto A. Bioactive peptides from food proteins. In: Hui YH, editor. USA: John Wiley \& Sons; 2007. p. 5-37.

13. Mishra LC, Singh RRB, Dagenais S. Scientific basis for the therapeutic use of Withania somnifera (Ashwagandha): A Review. Altern Med Rev. 2000;5(4):334-346.

14. Verma KC. Ashwagandha (Withania somnifera dunal): wonder medicinal plant. Agric Rev. 2010;31(4):292-297.

15. Niranjan A, Prakash D. Chemical constituents and biological activities of turmeric (Curcuma longa L.)-a review. J Food Sci Technol. 2008;45(2):109-116

16. Singh C, Saini NK, Manda H, et al. Evaluation of antioxidant activity of Terminalia arjuna leaves extract. Pharmacologyonline. 2011;1:998-1006.

17. Parmar P, Khamrui K, Devaraja HC, et al. The effects of alcoholic extract of Arjuna (Terminalia arjuna Wight \& Arn.) bark on stability of clarified butterfat. J Med Plant Res. 2013;7(35):2545-2550.

18. Shahid CSA, Hussain AI, Asad R, et al .Bioactive components and antioxidant properties of Terminalia arjuna L. extracts. $J$ Food Process Technol. 2014;5(1):298.

19. Cuvelier M, Berset C, Richard H. Antioxidant constituents in sage (Salviaofficinalis). J Agric \& Food Chem. 1994;42(3):665-669.

20. Zhang W, Xiao S, Samaraweera H, et al. Improving functional value of meat products. Meat Sci. 2010;86(1):15-31.

21. Lu YR, Foo YL. Antioxidant activities of polyphenols from sage (Salvia officinalis). Food Chem. 2001;75(2):197-202.

22. Jakhetia V, Patel R, Khatri P. Cinnamon: a pharmacological review. $J A d v$ Scientific Res. 2010;1(2):19-12.

23. Wondrak GT, Villeneuve NF, Lamore SD, et al. The cinnamon-derived dietary factor cinnamic aldehyde activates the Nrf2-dependent antioxidant response in human epithelial colon cells. Molecules. 2010;15(5):3338-3355.

24. Hossein N, Zahra Z, Abolfazl M, et al. Effect of Cinnamon zeylanicum essence and distillate on the clotting time. J Medicinal Plants Res. 2013;7(19):1339-1343.

25. Kim SH, Hyun SH, Choung SY. Anti-diabetic effect of cinnamon extract on blood glucose in db/db mice. J Ethnopharm. 2006;104(1-2):119-123.

26. NaveedR, Hussain I, Tawab A, et al. Antimicrobial activity of the bioactive components of essential oils from Pakistani spices against Salmonella and other multi-drug resistant bacteria. BMC Complementary \& Alternative Med. 2013;13:265. 
27. A1-Mariri A, Safi M. In vitro antibacterial activity of several plant extracts and oils against some Gram negative bacteria. Iran J Med Sci. 2014;39(1):36-43.

28. Hoquea MM, Barib ML, Juneja VK, et al. Antimicrobial activity of cloves and cinnamon extracts against food borne pathogens and spoilage bacteria, and inactivation of Listeria monocytogenes in ground chicken meat with their essential oils. Report Nat'l Food Res Inst. 2008;72(1):9-21.

29. Kaur D, Sharma R. An update on pharmacological properties of cumin. Int J Res Pharmacy \& Sci. 2012;2(4):14-27.

30. Iacobellis NS, Lo-Cantore P, Capasso F, et al. Antibacterial activity of Cuminum cyminum L. and Carumcarvi L. essential oils. J Agric Food Chem. 2005;53(1):57-61.

31. Derakhshan S, Sattari M, Bigdeli M. Effect of sub-inhibitory concentrations of cumin (Cuminum cyminum L) seed essential oil and alcoholic extract on the morphology, capsule expression and urease activity of Klebsiella pneumoniae. Int J Antimicrob Agents. 2008;32(5):432-436.

32. Hajlaoui H, Mighri H, Noumi E, et al. Chemical composition and biological activities of Tunisian Cuminum cyminum L. essential oil: A high effectiveness against Vibrio spp. strains. Food Chem Toxicol. 2010;48(8-9):2186-2192.

33. Dua A, Garg G, Balkar S, et al. Antimicrobial properties of methanolic extract of cumin (Cuminum cyminum). Int J Res in Ayurveda \& Pharm. 2013;4(1):104-107.

34. See comment in PubMed Commons beBorek C. Antioxidant health effects of aged garlic extract. J Nutr. 2001;131(3):1010-1015.

35. Ellmore GS, Feldberg RS. Allin lyase localization in bundle sheaths of thegarlic glove (Allium sativum). Am J Botany. 1994;81(1):89-94.

36. Kumar M, Berwal JS. Sensitivity of food pathogens to garlic (Alliumsativum). J Appl Microb. 1998;84(2):213-215.

37. Maidment DCF, Dembny Z, Harding. A study into the antibiotic effect of garlic Allium sativum on Escherichia coli and Staphylococcus albus. Nutr \& Food Sci. 1999;4:170-172.

38. Basu KT, Srichamrroen A. Health benefits of fenugreek. In: Watson RS, Preedy VR, editors. Bioactive Foods in Promoting Health: Fruits and Vegetables. 1sted. USA: Academic Press; 2010. p. 425-435.

39. Blumenthal M, Goldberg A, Brinckmann J. Herbal medicine. Expanded Commission E Monographs. Integrative Medicine Communications, USA; 2000. p. 297-303.

40. Balakrishnan A. Therapeutic uses of peppermint-A review. J Pharm Sci \& Res. 2015;7(7):474-476.

41. Prakash P, Gupta N. Therapeutic uses of Ocimum sanctum linn (tulsi) with a note on eugenol and its pharmacological actions: a short review. Indian J Physiol Pharmacol. 2005;49(2):125-131.

42. Hay RKM, Waterman PG. Volatile Oil Crops: Their Biology, Bio-Chemistry and Production. Longman Technical and Scientific, UK; 1993. p. $1-185$.

43. Baratta MT, Dorman HJD, Deans SG, et al. Chemical composition, antimicrobial and antioxidative activity of laurel, sage, rosemary, oregano and coriander essential oils. J Essential Oil Res. 1998;10(5):618-627.

44. Cuvas Limón RB, Julio MS, Carlos CEJ, et al. Aloe vera and Probiotics: A new alternative to symbiotic functional foods. Annual Res \& Rev Biology. 2016;9(2):1-11.

45. Hirasa K, Takemasa M. The Patterning Theory of Spice Use. In: Dekker M, editor. Spice - Science and Technology. USA: CRC Press; 1998. p. 85-140.
46. Hosseinzadeh H, Karimi GR, Ameri M. Effects of Anethum graveolens $L$. seed extracts on experimental gastric irritation models in mice. $B M C$ Pharmacology. 2002;2:21.

47. Bortolin E, Boniglia C, Calicchia A, et al. Irradiated herbs and spices detection: light-induced fading of the photo-stimulated luminescence response. Int J Food Sci Technol. 2007;42(3):330-335.

48. Lang Q, Wai CM. Supercritical fluid extraction in herbal and natural product studies-a practical review. Talanta. 2001;53(4):771-782.

49. Najgebauer Lejko D, Grega T, Sady M, et al. The quality and storage stability of butter made from sour cream with addition of dried sage and rosemary. Biotech Anim Husbandry. 2009;25(5-6):753-761.

50. Rajanikant, Patil GR. Development of process for herbal ghee. National Dairy Research Institute. 2005;10(2):8.

51. Pandey N, Chaurasia JK, Tiwari OP, et al. Antioxidant properties of different fractions of tubers from Pueraria tuberosa Linn. Food Chem. 2007;105(1):219-222.

52. Pawar N, Gandhi K, Purohit A, et al. Effect of added herb extracts on oxidative stability of ghee (butter oil) during accelerated oxidation condition. J Food Sci Technol. 2014;51(10):2727-2733.

53. Thomsen M. Shatavari - Asparagus racemosus. 2002.

54. Sharma PV. Dravyaguna Vigyan, Chowkambha Sanskrit Sansthan. 2nd ed. India: Chaukhambha Bharti Academy, 1998. p. 120-123.

55. Goyal RK, Singh J, Lal H. Asparagus racemosus-an update. Indian J Med Res. 2003;57(9):408-414.

56. Bhatnagar M, Sisodiya SS, Bhatnagar R. Antiulcer and antioxidant activity of Asparagus racemosus Willd and Withania somnifera Dunal in rats. Annals of the New York Acad Sci. 2005;1056:261-270.

57. Özcan M. Antioxidant activity of rosemary, sage and sumac extracts and their combinations on stability of natural peanut oil. J Med Food. 2003;6(3):267-270.

58. Estévez M, Ramirez R, Ventanas S, et al. Sage and rosemary essential oils versus BHT for the inhibition of lipid oxidative reactions in liver pâté. LWT-Food Sci Technol. 2007;40(1):58-65.

59. Behrad S, Yusof MY, Goh KL, et al. Manipulation of probiotics fermentation of yogurt by cinnamon and licorice: effects on yogurt formation and inhibition of Helicobacter pylori growth in vitro. Int Scholarly \& Sci Res \& Innovation. 2009;3(12):563-567.

60. Chowdhury BR, Chakraborty R, Raychaudhuri U. Study on beta-galactosidase enzymatic activity of herbal yogurt. Int J Food Sci Nutr. 2008;59(2):116-122.

61. Otaibi MA, Demerdash HE. Improvement of the quality and shelf life of concentrated yoghurt (labneh) by the addition of some essential oils. Afr JMicrob Res. 2008;2(7):156-161.

62. Thabet HM, Nogain QA, Abdoalaziz O, et al. Evaluation of the effects of some plant derived essential oils on shelf life extension of Labneh. Merit Res J Food Sci \& Technol. 2014;2(1):8-14.

63. Gandhi K, Lal D. Potential of herbal neutraceuticals in ghee- A Review. 2014.

64. Kumar Santosh T, Arvindakshan P, Sangeetha A, et al. Development of mint flavoured yoghurt spread. Asian J Dairy \& Food Res. 2013;32(1):19-24.

65. Landge UB, Pawar BK, Choudhari DM. Preparation of shrikhand using ashwagandha powder as additive. J Dairying Foods \& Home Sci. 2011;30(2):79-84.

66. Pinto SV, Patel AM, Jana AH, et al. Evaluation of different forms of ginger as flavouring in herbal ice cream. Int J Food Sci Technol Nutr. 2009;3(1-2):73-83. 
67. Trivedi V, Prajapati J, Pinto S, et al. Use of basil (tulsi) as flavouring ingredient in the manufacture of ice cream. Am Int J Contemp Res. 2014;1(3):28-43.

68. Buch Shweta, Pinto Suneeta, Aparnathi KD. Evaluation of efficacy of turmeric as a preservative in paneer. J Food Sci \& Technol. 2014;51(11):3226-3234.
69. Bandyopadhyay M, Chakraborty R, Raychaudhar U. Incorporation of herbs into sandesh, an Indian sweet dairy product, as a source of natural antioxidants. Int J Dairy Technol. 2007;60(3):228-233.

70. Samy S. Antimicrobial activity of essential oils against vancomycin-resistant enterococci and E. coli 0157: H7 in Feta soft cheese and minced beef meat. Brazilian J Microb. 2011;42(1):187-196. 